\title{
Determination of mineral content of commercial infant foods in the United Kingdom
}

\author{
Nazanin Zand, Francis B. Zotor, Babur Chowdhry, John Tetteh, Dave Wray and Paul Amuna \\ School of Science, University of Greenwich,, Kent ME4 4TB, UK
}

Good early infant feeding provides nutrients for optimal growth and development. Phenotypic expressions of food preferences in childhood which may persist into later life, however, depend on interactions between genetic predispositions and the early-life eating environment ${ }^{(1,2)}$. Increasing parental reliance on commercially marketed complementary foods in the UK has potential implications for total energy and fat intake and taste acquisition which may impact negatively on the risk of chronic non-communicable disease. The primary objective of this study is to examine nutritive values of complementary infant foods on the UK market in order to ascertain their suitability relative to dietary guidelines for the 6 to 9-month age group. Quantitative analyses of four popular brands currently on sale in the UK were conducted including mineral analysis which is the subject of this paper.

Meat and vegetable-based samples of same recipes of the four brands of infant food were analysed. Following microwave digestion of food samples, minerals were quantitatively measured in triplicate by inductively coupled plasma-optical emission spectroscopy (ICP-OES).

The preliminary results presented as per $100 \mathrm{~g}$ (Table 1) show considerable variability between samples with respect to mineral content. Vegetable-based recipes contained significantly more Ca than meat-based varieties $(P=0.01)$.

Table 1. Mineral content of four popular brands of infant complementary in the United Kingdom (mg per $100 \mathrm{~g}$ )

\begin{tabular}{|c|c|c|c|c|c|c|c|}
\hline \multirow[b]{2}{*}{ Minerals } & \multicolumn{3}{|c|}{ Meat-based } & \multicolumn{3}{|c|}{ Vegetable-based } & \multirow[b]{2}{*}{$P$-value } \\
\hline & Mean & $\mathrm{SD}$ & $\overline{\% \mathrm{RNI}}$ & Mean & $\mathrm{SD}$ & $\overline{\% \mathrm{RNI}}$ & \\
\hline Calcium & 17.4 & 9.4 & 3 & 56.4 & 19.7 & 11 & $\overline{0.01}$ \\
\hline Iron & 0.8 & 0.4 & 10 & 0.5 & 0.4 & 6 & 0.46 \\
\hline Zinc & 0.54 & 0.14 & 11 & 0.34 & 0.10 & 7 & 0.07 \\
\hline Magnesium & 12.0 & 2.7 & 16 & 12.7 & 3.4 & 17 & 0.79 \\
\hline Copper & 0.05 & 0.02 & 18 & $<0.006 * *$ & - & - & - \\
\hline Potassium & 140 & 34 & 20 & 126 & 33 & 18 & 0.63 \\
\hline Sodium & 48.3 & 21.3 & 15 & 47.3 & 32.6 & 15 & 0.96 \\
\hline Selenium* & $<0.24 * *$ & - & - & $<0.24 * *$ & - & - & - \\
\hline
\end{tabular}

Despite wide individual variations within varieties, no significant differences were observed in $\mathrm{Fe}, \mathrm{Zn}, \mathrm{Mg}, \mathrm{K}$ and $\mathrm{Na}$ contents between meat- and vegetable-based products. With reference to RNI values for 6 to 9 month olds, all samples provided less than $20 \%$ of RNI values except for K $(20 \%)$ with mean $(\mathrm{SD})$ values of $14.37( \pm 7.6) \%$ and $10.61( \pm 7.91) \%$ for meat- and vegetable-based recipes, respectively.

These results suggest that commercial complementary infant foods on the UK market may not contain minimum levels of minerals required for labelling the declaration of micronutrient content (Commission Directive 2006/125/EC). This provides opportunities and scope for product optimisation to improve their nutritive value.

1. Stang J (2006) Improving the eating patterns of infants and toddlers. $J$ Am Diet Assoc 106, S7.

2. Skinner JD, Carruth BR, Bounds W et al. (2002) Do food-related experiences in the first 2 years of life predict dietary variety in school-aged children? $J$ Nutr Educ Behav 34, 310 